\title{
ICTs and Time Use Behavior of the Students: A Study of Bangabandhu Sheikh Mujibur Rahman Science and Technology University, Gopalganj, Bangladesh
}

\author{
Md Abdur Rashid ${ }^{1, *}$, Md. Noman Amin², Shamsul Arefin², Md. Anisur Rahaman² \\ ${ }^{1}$ Department of Sociology, Hajee Mohammad Danesh Science and Technology University, Dinajpur, Bangladesh \\ ${ }^{2}$ Department of Sociology, Bangabandhu Sheikh Mujibur Rahman Science and Technology University, Gopalganj, Bangladesh \\ *Corresponding author: rashidm@unbc.ca
}

Received July 01, 2018; Revised August 02, 2018; Accepted August 15, 2018

\begin{abstract}
Within this global information and communication era, ICTs became the indispensable medium of daily communication, entertainment and education among the students of Bangladesh. Studies showed that students' attachment with ICTs and its uses have great impact on their academic performance. It may either enhance or degrade their academic ability based on their using behavior. This study is followed to discover students time use behavior along with the arena that ICTs are generally serving and conducted among the students of Bangabandhu Sheikh Mujibur Rahman Science and Technology University (BSMRSTU), Gopalganj by using survey research design. Among the students, 347 were selected as the respondents and data has been collected by using structured questionnaire. Results revealed that students are mostly attached to at least one component of ICTs and use it everyday ranging one hour to more than five hours. They make use of it for the purpose of education, communication, entertainment and passing leisure time. However, this study will guide further researches to correlate students' time use behavior and its impact on their career.
\end{abstract}

Keywords: ICTs, time use behavior, students, BSMRSTU

Cite This Article: Md Abdur Rashid, Md. Noman Amin, Shamsul Arefin, and Md. Anisur Rahaman, "ICTs and Time Use Behavior of the Students: A Study of Bangabandhu Sheikh Mujibur Rahman Science and Technology University, Gopalganj, Bangladesh.” American Journal of Educational Research, vol. 6, no. 8 (2018): 1164-1171. doi: 10.12691/education-6-8-15.

\section{Introduction}

"The modern era is the period of technological development and progress" [1]. ICTs penetrate in every sphere of human life. Now people make use of it instead of using other daily communication instruments. Within this global trend, Bangladeshis are not an exception. The report of International Telecommunication Union (2016) describes the current status of ICTs in Bangladesh as:

"Bangladesh has witnessed rapid expansion of $3 \mathrm{G}$ networks which is significantly impacting the growth of mobile-broadband users and it is looking forward to introduce LTE technology. However, fixed Internet penetration is increasing day by day as several initiatives and policies have been formulated and implemented by the Government of Bangladesh to successfully achieve the vision of "Digital Bangladesh"” $[2]$.

In January 2018, Bangladesh Telecommunication Regulatory Commission (BTRC) recorded a total number of 147.0 million mobile phones subscribers around the country that is nearly double of the subscribers of 2012 [3]. Internet Live Stats counted 21,439,070 internet users in Bangladesh up-to 2016 that was $13.2 \%$ of total population [4]. These reports ensured that Bangladesh is entering into the realm of ICTs advanced countries. Along with the inclusion of ICTs people are gradually adopting it in their daily lives. Modern electronic media like satellite TV, internet and computer have become a part and parcel of daily life of the youths in Bangladesh. With the inclusion and ease accessibilities of global media, the program hosted in our local TV on local culture became insignificant among the youth. Most of the youths use computer more than an hour for the purpose of chatting, playing game, listening music, watching movies and for mailing [5].

Individual attachment with ICTs and use of it is varied along with their different attainments and attributes. There is a link between a person's educational attainment and use of ICTs. The higher an individual enrolled in higher academic level the higher the rate of their engagement with ICTs. It is also evident that students are more likely to use ICTs than the senior citizen of a country (See Figure 1) [2]. 


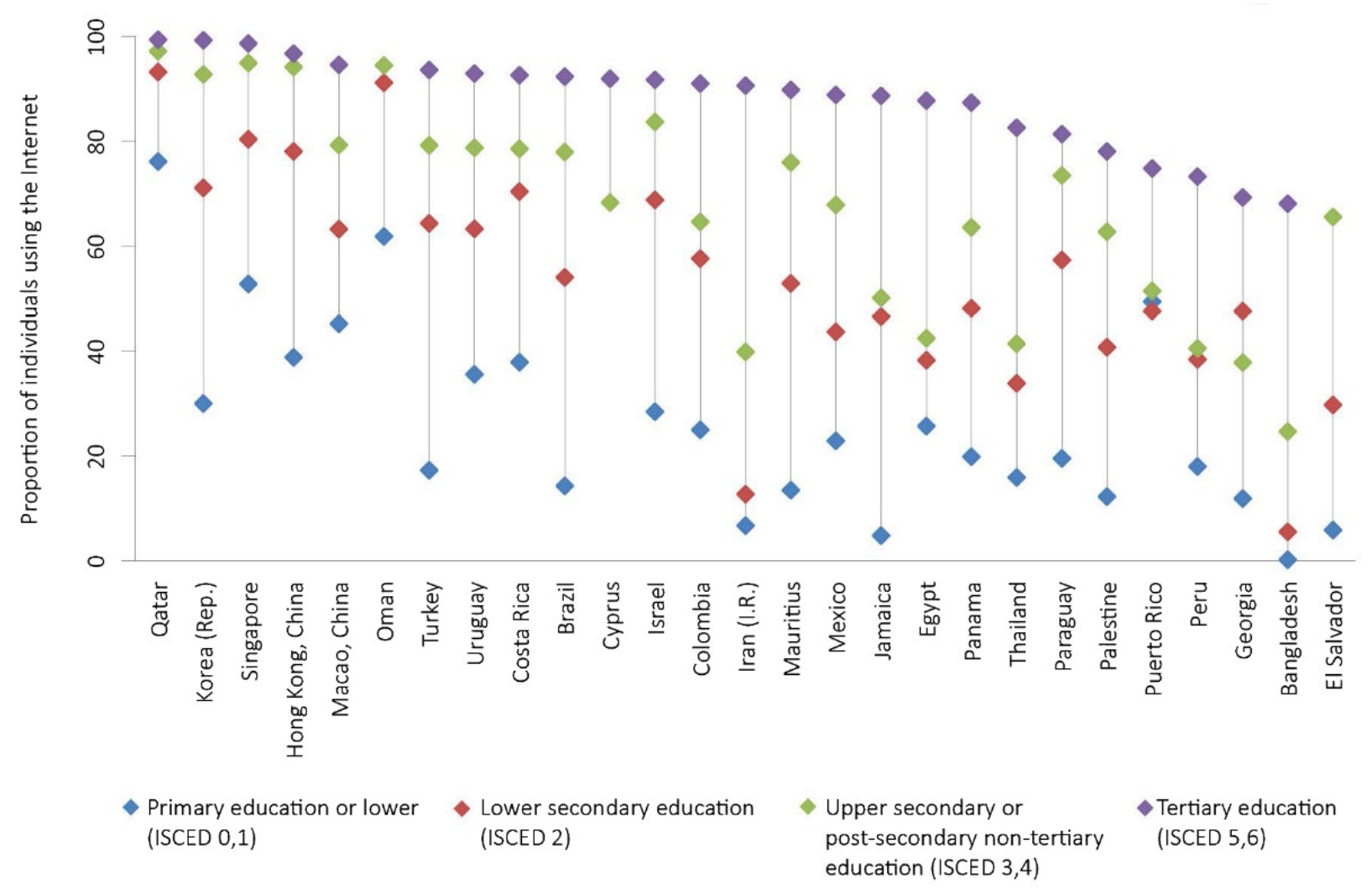

Figure 1. Internet use by level of education in developing countries (latest data 2013-2015) [2]

Punie, Zinnbauer \& Cabrera (2006) claimed that, "it is difficult and may be even impossible to imagine future learning environments that are not supported, in one way or another, by Information and Communication Technologies (ICTs)" [6]. ICTs and student performance in higher education are highly interrelated. A student can either enhance their ability or waste their time- causing degradation of their performance- by using ICTs [7]. Following a study, conducted on ASA university- Bangladesh, Islam \& Fouji (2010) found that there is no impact of ICT on student better performance as most of the student have been using ICT for listening music, watching movies and unnecessary internet browsing rather using it for educational purposes. Taking everything into consideration, this study aims to characterize the time use patterns of students after ICTs and selected 347 students from Bangabandhu Sheikh Mujibur Rahman Science and Technology University, Gopalganj for the study. This study also tries to draw out an overall scenario of Bangladesh in this context.

\section{Literature Review}

The spread of computers, internet, smart-phone, iPod and similar communication and information technologies have altered the realm of social life. Individual social relationships are being reorganized. The influences of ICTs are also observed for the case of education ranging from primary to tertiary level. Students are increasingly reliant on computer and for information on internet. Long (2010) investigates how young adults use digital communication technologies and the ways that social relationships are shaped by these new technologies. The question of how internet and other new technologies are affecting social lives of youth is hotly debated. Understanding this phenomenon is important as internet culture and digital technologies continue to expand their role in society. He argued that social life in the United States is changing rapidly with the growing use of Web 2.0 technologies [8].

"Even personal life, ranging from family life to friendship to intimate relationships are being affected by these new technologies as all kinds of social interactions are mediated by technology" [8].

Brignall (2005) suggests that "face-to-face interaction among youth shrinks due to the fact that relationships are increasingly conducted via cell phones, text messaging, instant messaging, social networking sites and blogs, therefore their ability to develop and maintain social skills and relationships are affected" [8].

Nonetheless, it is obvious that in this information age, social interactions that occur through these various technologies have facilitated wider networks and increased methods of connectivity. Several studies have found that, "student can perform well throughout the usage of ICTs. ICTs help the students to augment their knowledge skills as well as to improve their learning skills" [9].

There exists a correlation between individual attachment with technology and its impact on their health status. A study by Muduli (2014) conducted at NIT campus Rourkela, India, where 150 students had participated, found adverse relationship in the health of individual derived from intensive technology uses. Among the 150, most of them were youth and possess two or more than two technological gadgets. Most of them are using their 
gadgets above 6 hours- mostly for using internet. He found that people who are using ICTs for a long period have negative impacts on their health. Individual who use earphones for more than 6 hours have hearing problems as compared to the others. Respondents who passed time with their gadgets for more than 6 hours are having several problems like problems in logical thinking, headaches, depression, anxiety, etc. Respondents of the same category also have problems in sleeping, excessively worrying, afraid of public speaking and have low consciousness. These problems are seen less common among those who use gadgets less than six hours. However, correlation between ICTs and health can be summarized as higher the rate of individual attachment with ICTs the higher the chances of facing physical problems [10]. Again, Muduli (2014) found that addiction to tech-gadgets has impacts on life style of the respondents. People often gradually become lazy when they are more dependent on ICTs. This dependency on ICTs creates problem in human body as it separates them from the physical working environment [10]. They usually prefer indirect communication rather than physical meeting. A certain level of mental problem arises when they stay alone for longtime [1].

Considering these statements this study aims to discover students time using behavior and its frequency over a period of time. As previous studies suggest that individuals have several impacts comprises from their attachment with ICTs, this study will guide policy maker to take initiative in the arena of controlling their behavior and further researchers who want to deal with students' attachment with ICTs and its impact on their career and body structure.

\section{Theoretical Background}

As the beginning of 21 st century witnessed a higher proportion of technological innovation, now the process of adopting new innovation has become a hotly debated topic among the researchers. The most popular technology diffusion and adoption model is described by Rogers which he developed in his book Diffusion of Innovation [11]. Rogers (1983) defines adoption as "full use of an innovation as the best course of action available" and rejection of an innovation is a decision "not to adopt an innovation" (p. 172) [12]. Innovations are not dramatically adopted by all individual at a same time in a given society. In contrast ideas and materials are adopted by the people within a course of time. The time frame depend on how the invention is much more related with the individuals. The members of a society adopt new ideas by individual human interaction through interpersonal networks. Initial adopter acts as an agent for the diffusions of an innovation. They discuss it among their peer groups and their individual practices create a picture of it among their surroundings. Later these early adopters pass the innovation to other parts of the society [12].

Rogers (1983) defined 'rate of adoption' as “the relative speed with which an innovation is adopted by members of a social system" (p. 232) [12]. He mentioned different independent variables that determine the rate of adoption of an innovation. He proposes 'attributes of innovation' that help individual to quickly adapt an innovation and reduce uncertainty about the innovation. It includes five characteristics of the innovations: (1) relative advantage, (2) compatibility, (3) complexity, (4) trialability, and (5) observability [12].

Relative Advantage "is the degree to which an innovation is perceived as better than the idea it supersedes". Compatibility a degree to which an "innovation is perceived as consistent with the existing values, past experiences, and needs of potential adopters". Complexity "is the degree to which an innovation is perceived as relatively difficult to understand and to use". Triability "is the degree to which an innovation may be experimented with on a limited basis". Observability "is the degree to which the results of an innovation are visible to others" [12].

Rogers (1983) categorized 'adopter' based on individual innovative characteristics: a degree on which some people are tend to adapt new ideas and have a sense of obsession towards the innovators. This degree varies person to person as some people are eager to adapt another idea more than others. He termed them as venturesome and accordingly categorized them into five segments [12].

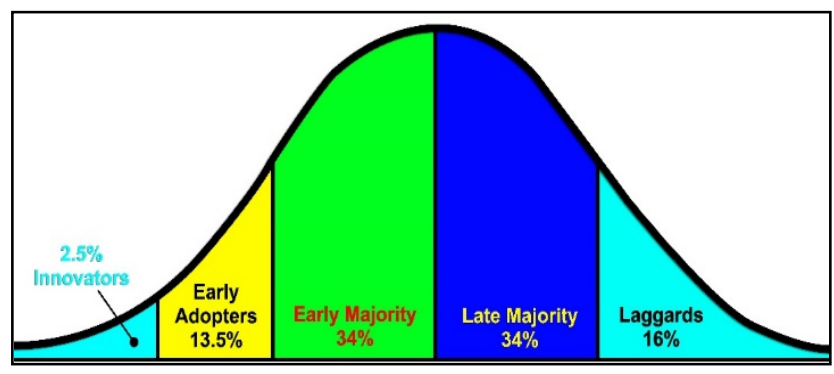

Figure 2. Adopter categorization on the basis of innovativeness [12]

The first category of adopter is the innovators who are the first to try an innovation. Their inner ability always derives them to seek the experiences of the new ideas. They constitute $2.5 \%$ of the population. Rogers (1983) declared that early adopter are more likely to apprehend leadership position as other member of the society come to them to take advice or information about the new innovation. Their obsession towards the new innovation support innovator in the diffusion processes [11]. These early adopters comprise $13.5 \%$ who are in touch with the innovators. After the early adopter a group of early majorities, who constitute $34 \%$, practices or adopt new innovation when the major portion of the society are not aware or not yet practices. Although they do not hold leadership position but continuously they interact with the people. Their engagement with the new ideas lead them an important position in the diffusion process. Late majority are those people who came after the early majority. Their adoptions may be for the sake of economic interests or the increasing network pressures. Laggards have traditional outlook and are much more conservative. They do not hold leadership role as they are skeptical on the innovation, have limited resources and lack of awareness-knowledge of innovations. They always seek time to see the successful adoption of the innovation and for this their innovation-decision period is so long [12]. These late majorities and laggard groups constitute $34 \%$ and $16 \%$ respectively. 
Rogers' model of the rate of adoption can be addressed by the modern people of Bangladesh. In Bangladesh, ICTs penetrate within its mainstream institution during 1960s by the nuclear research center. As it bring out new facilities, advantages and ease ways of communication module, the use of ICTs in different institution has increased gradually over next few decades. Now adoption rate is so intense that is addressed by different reports [see 2-4]. The adoption rate will also clear from the below Table 1.

Table 1. Internet Users in Bangladesh over a Period of Time

\begin{tabular}{ccc}
\hline Year & Internet Users** & Penetration (\% of Pop) \\
\hline $2016^{*}$ & $21,439,070$ & $13.2 \%$ \\
2015 & $19,420,674$ & $12.1 \%$ \\
2014 & $15,271,441$ & $9.6 \%$ \\
2012 & $7,762,869$ & $5 \%$ \\
2006 & $1,448,392$ & $1 \%$ \\
2000 & 93,261 & $0.1 \%$ \\
\hline
\end{tabular}

Note. * estimate for July 1, 2016; ** Internet User = individual who can access the Internet at home, via any device type and connection.

Source: Internet Live Stats (www.InternetLiveStats.com)

\section{Methodology}

This study is conducted among the students of Bangabandhu Sheikh Mujibur Rahman Science and Technology University, Gopalganj, Bangladesh. As this study aims to uncover students' time-consuming behavior, purposively we have employed survey research design. In order to accumulate a representative sample, respondents were selected from each and every academic session. Students from different department are also taken into consideration while selecting the sample.

As of 2017, university website recorder a total number of 5594 students from the academic session of 2012-2013 to 2016-2017. Students are defined as first year, second year, third year, fourth year and master's level according to their academic status in 2017. To reach gender equilibrium, total proportion of the students are divided into two segments as $70 \%$ as male and $30 \%$ as female (based on male-female ratio of the report of UGC, 2016 [13]). From the two-stratum of population, sample are taken at the rate of $6 \%$ from males and $7 \%$ from females proportion. After calculation through the above procedure, total number of samples reached to 347. Regarding the distribution and number of departments in each academic session, respondents are taken respectively.

Table 2. Distributions of the Population and Sampling for Survey Data

\begin{tabular}{|c|c|c|c|c|c|c|}
\hline \multirow[b]{2}{*}{ Academic Year } & \multirow[b]{2}{*}{ Students } & \multirow[b]{2}{*}{ Dept. } & \multicolumn{2}{|c|}{ Male } & \multicolumn{2}{|r|}{ Female } \\
\hline & & & $70 \%$ & $\begin{array}{c}\text { Sample } \\
(6 \%)\end{array}$ & $30 \%$ & Sample $(7 \%)$ \\
\hline Hon's (1 ${ }^{\text {st }}$ year $)$ & 2207 & 23 & 1545 & 92 & 662 & 47 \\
\hline Hon's ( $2^{\text {nd }}$ year $)$ & 1450 & 20 & 1015 & 61 & 435 & 26 \\
\hline Hon's ( $3^{\text {rd }}$ year) & 747 & 14 & 523 & 32 & 224 & 14 \\
\hline Hon's ( $4^{\text {th }}$ year) & 670 & 14 & 469 & 28 & 201 & 14 \\
\hline Masters & 520 & 11 & 364 & 22 & 156 & 11 \\
\hline Total & 5594 & & & 235 & & 112 \\
\hline
\end{tabular}

Respondents are being asked through a structured questionnaire that is mailed through online media. Some of them are being asked directly by the researchers along with the questionnaire. In this study we mean ICTs to only mobile phones, computers and camera devices. As a ICTs component, students' access to internet is also taken into consideration for this study. In the first section, they are being questioned about their attachment with ICTs and later activities with ICTs have been asked along with a time-table distribution.

\subsection{Characteristics of the Sample}

Table 3. Age Structure of the Respondents

\begin{tabular}{lcc}
\hline & Frequency $(\mathrm{n})$ & Percent $(\%)$ \\
\hline Age distributions & & \\
$18-20$ & 66 & 19.0 \\
$21-25$ & 276 & 79.5 \\
$26-30$ & 5 & 1.4 \\
Total $(\mathrm{N})$ & 347 & 100.0 \\
\hline
\end{tabular}

This study found that most of the students in tertiary level education are belong to the age group of 18-30 where most of them belongs to 21-25 age group.

\section{Results}

\subsection{Students' Possession of ICTs}

As this study was intended to discover the time use behavior, so students' attachment to ICTs was needed to be explored. Students were asked whether they have the mobile phone, computer and camera device or not. Results shows that among the 347 respondents, 100\% have any kind of mobile devices where $88.2 \%$ possessed smartphone featured with the broadband cellular network connection for voice, SMS and internet, sometimes called as handheld pocket computer as it supports the major systematic arrangements for performing the computer oriented programs; $5.2 \%$ have only a classic phone featured with the basic cellular communication module i.e., voice calling, text messaging and sometimes gaming and multimedia messaging. Significantly $6.6 \%$ of the respondents have both smartphone and classic phone.

Table 4. Respondents' Possession of the Technologies

\begin{tabular}{lcc}
\hline & Frequency (n) & Percent (\%) \\
\hline Mobile phone user and types of mobile & & \\
Smartphone/ Tab & 306 & 88.2 \\
Classic phone & 18 & 5.2 \\
Both Smartphone and Classic phone & 23 & 6.6 \\
Have not any phone & 00 & 0.0 \\
Total & 347 & 100.0 \\
Respondent's computer attachment & & \\
Desktop & 38 & 11.0 \\
Laptop & 125 & 36.0 \\
Both Desktop and Laptop & 10 & 2.9 \\
Have not any computer & 174 & 50.1 \\
Total & 347 & 100.0 \\
Respondent's camera ownership & & \\
Have a camera device & 63 & 18.2 \\
Have not any camera devices & 284 & 81.8 \\
Total & 347 & 100.0 \\
\hline
\end{tabular}


Among 347 respondents, 11\% have desktop model computer, $36 \%$ have Laptop computer and $2.9 \%$ have both desktop and laptop model computer. Among the total 347 respondents, $50.1 \%$ have not any kind of computer. Sometimes student's possession of camera devices fuels their activities in the arena of ICTs, so respondents are being asked whether they have a camera device or not. Result shows that significantly $18.2 \%$ of the respondents possessed any type of solid camera devices.

\subsection{Access to Internet}

This study revealed that most of the students are using internet as among the 347 students, $96 \%$ of them are using internet and the others $4 \%$ are not using internet (see Figure 3). Among this group some of them have opined that they are using internet on an occasional scale. So, all of the respondents have the experience of using internet.

\subsection{Time Distributions for the Activities Students Spend with Internet}

In this study a group of different time tables have been distributed to know how much time students spend with internet to perform listed major tasks. Surprisingly it is revealed that internet or other ICTs have created a new dimension where students are regularly engaged in. After analyzing the responses, following frequency table revealed that most of the students spend time for using social media where 133 of them generally spend at least less than an hour in a day. Significantly 120 of them are use social media on a basis of 1 to 2 hours in a day. This study also found that a portion of the students is using social media for 3 to 4 hours in a day. Among the 347 respondents, 127, 105 and 27 of them used internet for collecting information and study topics associated with them on the time scale of less than 1 hours in a day, 1-2 hours in day, 3-4 hours in a day respectively (see Table 5).

Among the total sample of 347, 193 and 56 of them use internet to read newspaper; 37 and 14 of them use internet to perform online job; 99 and 18 of them use internet for writing blog and sending or receiving mail on the time scale of less than 1 hours in day and 1-2 hours in a day respectively. A limited distribution (146 of 347) opined that they use internet for watching pornography.

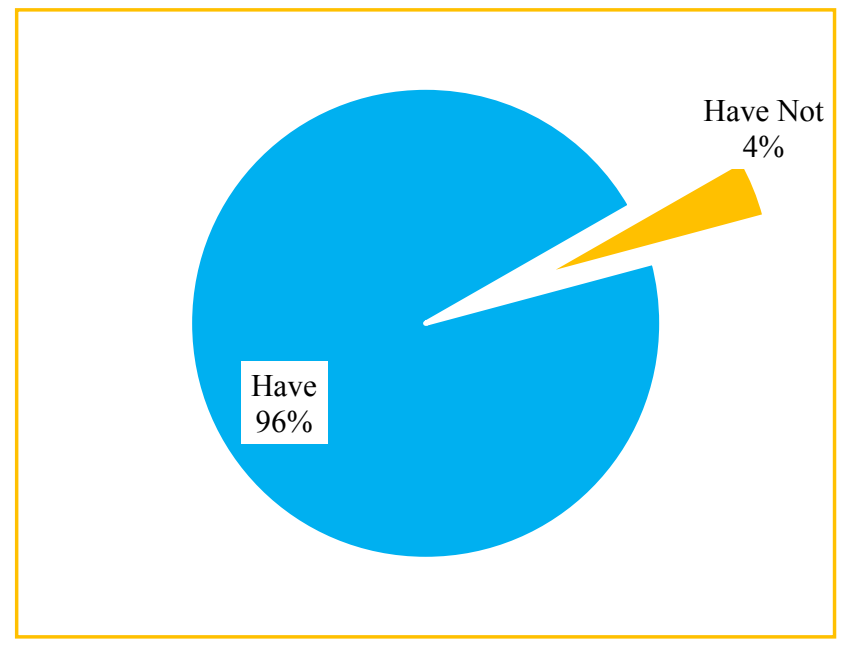

Figure 3. Status of the respondents' access to internet (Note. Total Respondents $(\mathrm{N})=347$ )

Table 5. Distributions of the Activities and Time Students Spend with Internet

\begin{tabular}{|c|c|c|c|c|c|c|c|c|c|}
\hline Arena of using internet & 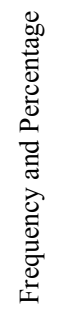 & 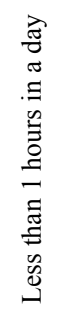 & 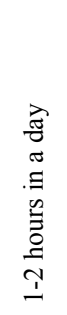 & 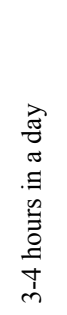 & 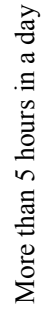 & 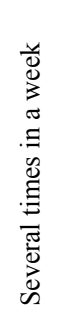 & 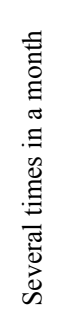 & 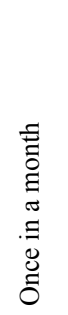 & 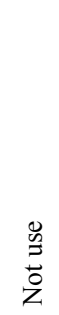 \\
\hline \multirow{2}{*}{ To use social media } & (n) & 133 & 120 & 35 & 31 & 8 & 4 & 2 & 14 \\
\hline & $(\%)$ & 38.3 & 34.6 & 10.1 & 8.9 & 2.3 & 1.2 & 0.6 & 4.0 \\
\hline \multirow{2}{*}{ To collect information and study topics } & (n) & 127 & 105 & 27 & 10 & 34 & 15 & 5 & 24 \\
\hline & $(\%)$ & 36.6 & 30.3 & 7.8 & 2.9 & 9.8 & 4.3 & 1.4 & 6.9 \\
\hline \multirow{2}{*}{ To read news } & (n) & 193 & 56 & 12 & 5 & 22 & 19 & 1 & 39 \\
\hline & $(\%)$ & 55.6 & 16.1 & 3.5 & 1.4 & 6.3 & 5.5 & 0.3 & 11.2 \\
\hline \multirow{2}{*}{ To see or download videos } & (n) & 103 & 72 & 35 & 12 & 35 & 12 & 11 & 67 \\
\hline & $(\%)$ & 29.7 & 20.7 & 10.1 & 3.5 & 10.1 & 3.5 & 3.2 & 19.3 \\
\hline \multirow{2}{*}{ To perform online job } & (n) & 37 & 14 & 6 & 5 & 10 & 3 & 4 & 268 \\
\hline & $(\%)$ & 10.7 & 4.0 & 1.7 & 1.4 & 2.9 & 0.9 & 1.2 & 77.2 \\
\hline \multirow{2}{*}{ To send or check mail or write blog } & (n) & 99 & 18 & 0 & 3 & 15 & 12 & 19 & 181 \\
\hline & $(\%)$ & 28.5 & 5.2 & 0.0 & 0.9 & 4.3 & 3.5 & 5.5 & 52.2 \\
\hline \multirow{2}{*}{ To watch pornography } & (n) & 14 & 6 & 6 & 0 & 27 & 57 & 36 & 201 \\
\hline & $(\%)$ & 4.0 & 1.7 & 1.7 & 0.0 & 7.8 & 16.4 & 10.4 & 57.9 \\
\hline
\end{tabular}

Note. Total Respondents $(\mathrm{N})=347$. 


\subsection{Time Distributions for the Activities Students Spend with Mobile Phone}

Students are regularly using mobile phone for the purpose of communication with their fellowmen. In this study we found that $58.2 \%, 21.6 \%$ and $10.4 \%$ of the total 347 respondents have used mobile phone on the time scale of less than one hour in a day, 1-2 hours in a day and 3-4 hours in a day respectively. Students who have a smartphone or a classic phone are using it for the purpose of playing game where $48.4 \%$ of them are using it everyday for the time ranging from 1 to 5 hours. A large number of the distributions (79.3\% of the total 347 ) has used mobile phone for educational purpose; $47.3 \%$ respondents have used for the purpose of taking photo; and $77.4 \%$ respondents have used it for watching videos everyday on the time frame of 1 to more than 5 hours in a day (see Table 6).

\subsection{Time Distributions for the Activities Students Spend with Computer}

Respondents who have computer devices significantly spend time for various purposes. In a timetable distribution, they are being asked to answer how much time they need to perform some specific task where 177, 92 and 125 of the total respondents of 347 have affirmed that they use computer for the purposes of watching videos, playing game and preparing assignment or other study purposes respectively in everyday on the time ranging less than one hour to more than five hours in a day (see Table 7).

Table 6. Distributions of the Activities and Time Students Spend with Mobile Phone

\begin{tabular}{|c|c|c|c|c|c|c|c|c|c|}
\hline Arena of using mobile phone & 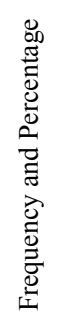 & 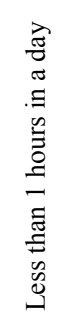 & 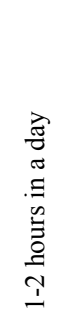 & 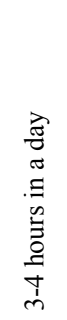 & 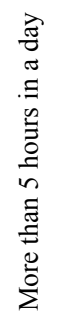 & 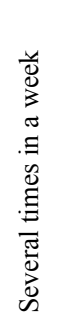 & 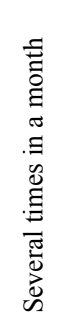 & 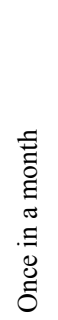 & $\begin{array}{l}0 \\
\triangleq \\
\Xi \\
0 \\
z\end{array}$ \\
\hline \multirow{2}{*}{ To communicate with other } & (n) & 202 & 75 & 36 & 11 & 14 & 1 & 1 & 7 \\
\hline & $(\%)$ & 58.2 & 21.6 & 10.4 & 3.2 & 4.0 & 0.3 & 0.3 & 2.0 \\
\hline \multirow{2}{*}{ To play game } & (n) & 109 & 45 & 13 & 1 & 6 & 12 & 3 & 158 \\
\hline & $(\%)$ & 31.4 & 13.0 & 3.7 & 0.3 & 1.7 & 3.5 & 0.9 & 45.5 \\
\hline \multirow{2}{*}{ To use internet } & (n) & 111 & 87 & 68 & 29 & 17 & 5 & 2 & 28 \\
\hline & $(\%)$ & 32.0 & 25.1 & 19.6 & 8.4 & 4.9 & 1.4 & 0.6 & 8.1 \\
\hline \multirow{2}{*}{ For educational purpose } & (n) & 155 & 79 & 23 & 18 & 25 & 15 & 5 & 27 \\
\hline & $(\%)$ & 44.7 & 22.8 & 6.6 & 5.2 & 7.2 & 4.3 & 1.4 & 7.8 \\
\hline \multirow{2}{*}{ To take photo } & (n) & 130 & 25 & 7 & 2 & 30 & 48 & 18 & 87 \\
\hline & $(\%)$ & 37.5 & 7.2 & 2.0 & 0.6 & 8.6 & 13.8 & 5.2 & 25.1 \\
\hline \multirow{2}{*}{ To watch video } & (n) & 108 & 107 & 40 & 14 & 18 & 19 & 8 & 33 \\
\hline & $(\%)$ & 31.1 & 30.8 & 11.5 & 4.0 & 5.2 & 5.5 & 2.3 & 9.5 \\
\hline
\end{tabular}

Note. Total Respondents $(\mathrm{N})=347$ 。

Table 7. Distributions of the Tasks and Time Students Spend with Computer

\begin{tabular}{|c|c|c|c|c|c|c|c|c|c|}
\hline Arena of using computer & 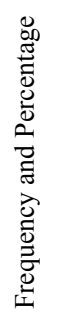 & 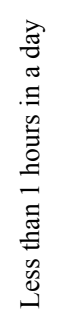 & 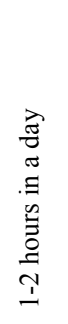 & 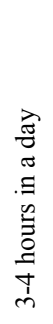 & 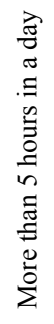 & 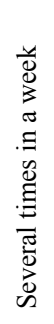 & 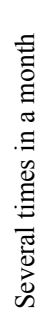 & 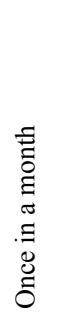 & 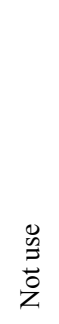 \\
\hline \multirow{2}{*}{ To watch video } & (n) & 85 & 55 & 28 & 9 & 10 & 17 & 6 & 137 \\
\hline & $(\%)$ & 24.5 & 15.9 & 8.1 & 2.6 & 2.9 & 4.9 & 1.7 & 39.5 \\
\hline \multirow{2}{*}{ To play game } & (n) & 58 & 26 & 6 & 2 & 8 & 7 & 0 & 240 \\
\hline & $(\%)$ & 16.7 & 7.5 & 1.7 & 0.6 & 2.3 & 2.0 & 0.0 & 69.2 \\
\hline \multirow{2}{*}{ To prepare assignment, presentation and so on } & (n) & 65 & 32 & 15 & 13 & 15 & 31 & 5 & 171 \\
\hline & $(\%)$ & 18.7 & 9.2 & 4.3 & 3.7 & 4.3 & 8.9 & 1.4 & 49.3 \\
\hline
\end{tabular}

Note. Total Respondents $(\mathrm{N})=347$.

Not use includes the respondents who have no computer. 


\section{Discussion}

ICTs became a daily tool that students are mostly associated with. This study shows that students are using ICTs specially computer, mobile phone and internet for either their necessary needs or passing leisure time. Now students are mostly dependent on technology. Previously students were tended to pass their time by gossiping with friends in a face-to-face setting, but now students are separated from the nature, from the people, and from himself. Media creates an attraction that generate attachment with it. Study shows that significant number of the students (about 93\% via mobile phone) make use of ICTs for their daily communication either via cellular phone-based calling or by internet-based calling. For the purpose of entertainment and passing leisure time students play games via mobile and computer $(26.5 \%$ via computer and $48.4 \%$ via mobile phone on a daily basis), watch movies and drama serials $(77.4 \%$ via mobile phone and $51.1 \%$ via computer on a daily basis) and gossip with friends through online media. In some cases, students became more addictive to irrelevant contents rather proper using it for their academic and career development.

Once students have registered with a social media account they can't avoid it. The features, content and so other conveniences attract them to be engaged in. In this study we found that everyday about $91 \%$ students use some types of social media. Some of them opined that after registering into a social media account they can't keep aloof from using it. They feel alone if in a course of time they separated from it. Study shows that these types of social media not only act as a means of bringing people together but also consume their time [1]. Everyday, when students go to the bed at 11.00PM for sleeping and want to check what happened in social media, it keeps them unslept at least 1 to 1.5 hours. Similarly, every time it costs their time when they open Facebook and begin to scroll down. Another time-consuming content is watching video through ICTs. If a student wants to watch a movie either instructive or uninstructive, normally it costs at least three hours in a day.

ICTs made the communication and education process easy and accessible to the students. Students use ICTs for the purpose of using dictionaries, calculator, browsing academic contents over internet, sending e-mails and so forth. In this study we found that everyday about $79 \%$ students use mobile phone and $77.6 \%$ use internet for their educational purpose. More than 35\% students make use of computer everyday for preparing their study materials i.e., assignment, presentation etc. Rogers suggested that "the relative advantage, compatibility, triability and observability of an innovation, as perceived by members of a social system, are 'positively related to its rate of adoption' and complexity is negatively related to its rate of adoption" $[1,12]$. As these "positive perception influenced their intention to adopt Internet in which the higher the relative advantage, the higher the rate of Internet adoption" [14]. Similarly, ICTs substitute several traditional forms of entertainment, gaming and passing leisure time in an ease procedure so that students are more engaged with it. As ICTs require some forms of expertise on the arena of language, reading, writing and so other cognitive competency, the rate of adoption is high among tertiary education level students rather than other age group. Thus, this study also supports the statements of 'International Telecommunication Union' (see Figure 1).

\section{Recommendation and Conclusion}

This study revealed that students use ICTs on an average of more than 5 hours in a day to perform various activities. If this trend continues over a period of time it may cause long term impact on their body and mind (i.e., see 10). Similarly it may cost their academic career if they continuously engaged with irrelevant contents. As it is a dependent variable, causal relationship may observe in different social arena e.g., cultural attributes, political causation and so forth. Previously, as usual, book was the companion of a student when the earth covered with a dark shadow and an object that placed on the hand of a student, but now mobile phone, laptop etc. substitute it. Students may either make proper use of it or humiliate them.

As youth are the future of a country so their time use behavior should be moderated. This study recommends the student to make proper use of time. Students should differentiate necessary and unnecessary contents in the realm of online media. Navigation to the irrelevant contents should be limited. Government and other respective authority may control harmful contents that persist in the realm of internet. As social media is referred as addictive by the respondents using time-frame can be imposed. Internet service provider should set restriction in navigating harmful contents.

\section{References}

[1] Amin, M. N. (2018). ICTs, Youths and Culture: A Sociological Study of Bangabandhu Sheikh Mujibur Rahman Science and Technology University, Gopalganj, Bangladesh (Masters). Bangabandhu Sheikh Mujibur Rahman Science \& Technology University, Gopalganj.

[2] International Telecommunication Union. (2016). Measuring the Information Society Report. Geneva Switzerland: International Telecommunication Union. Retrieved from https://www.itu.int/en/ITU-

D/Statistics/Documents/publications/misr2016/MISR2016-w4.pdf.

[3] BTRC. (2018). Mobile Phone Subscribers in Bangladesh January, 2018. Dhaka, Bangladesh: BTRC. Retrieved from http://www.btrc.gov.bd/content/mobile-phone-subscribersbangladesh-january-2018.

[4] Bangladesh Internet Users. (2016). Internetlivestats.com. Retrieved 6 March 2018, from http://www.internetlivestats.com/internet-users/bangladesh/.

[5] Zahid, D. (2007). Impact of Cultural Globalization on the Upper Class Youth in Dhaka City: A Sample Study. Bangladesh EJournal of Sociology, 4(2).

[6] Punie, Y., Zinnbauer, D., \& Cabrera, M. (2006). A Review of the Impact of ICT on Learning. Edificio Expo. c/ Inca Garcilaso, $s / n$. E-41092 Seville (Spain): European Commission, Joint Research Centre, Institute for Prospective Technological Studies.

[7] Islam, M. \& Fouji, M. (2010). The Impact of ICT on Students' Performance: A Case Study of ASA University Bangladesh. ASA University Review, 4(2), pp.101-106.

[8] Long, S. (2010). Exploring Web 2.0: The Impact of Digital Communications Technologies on Youth Relationships and Sociability (Bachelor of Arts). Occidental College. 
[9] Nisar, M., Munir, E., \& Shad, S. (2011). Usage and Impact of ICT in Education Sector; A Study of Pakistan. Australian Journal Of Basic And Applied Sciences, 5(12), 578-583.

[10] Muduli, J. R. (2014). Addiction to Technological Gadgets and Its Impact on Health and Lifestyle: A Study on College Students (Master's Degree). National Institute of Technology, Rourkela 769008 , India.

[11] Sahin, I. (2006). Detailed Review of Rogers' Diffusion of Innovations Theory and Educational Technology-Related Studies
Based on Rogers' Theory. The Turkish Online Journal of Educational Technology - TOJET, 5(2), pp.14-23.

[12] Rogers, E. (1983). Diffusion of innovations. New York: Macmillan.

[13] University Grants Commission of Bangladesh. (2016). Universities of Bangladesh (pp. 255-258). Sher-e-Bangla Nagar, Dhaka-1207: The University Grants Commission of Bangladesh. Retrieved from http://www.ugc.gov.bd/en/home/downloadfile/35.

[14] Azam, M. (2007). Internet Adoption and Usage in Bangladesh. Japanese Journal of Administrative Science, 20(1), pp.43-54. 